\title{
Estressores e atenuantes de estresse entre idosos em tratamento hemodialítico
}

\author{
Stressors and stress attenuating factors among elderly subjects in hemodialysis
}

Eniva Miladi Fernandes Stumm ${ }^{1}$, Paola Braz de Abreu², Liamara Denise Ubessi ${ }^{3}$, Dulce Aparecida Barbosa ${ }^{4}$

\begin{abstract}
RESUMO
Objetivo: Conhecer e analisar estressores e fatores atenuantes do estresse vivenciados por idosos que realizam hemodiálise.

Materiais e Métodos: Estudo qualitativo, com 15 idosos, realizado em 2010, em uma Unidade Renal hospitalar do noroeste do Rio Grande do Sul. Instrumentos de coleta de dados: entrevista semiestruturada, dados de caracterização e observações em diário de campo. Análise dos resultados seguiu preceitos da análise de conteúdo.

Resultados: O idoso pesquisado convive com vários estressores no seu cotidiano: restrições alimentar e hídrica, não poder trabalhar, dificuldade de aceitar a doença e tratamento, deslocamento para tratamento, fraqueza, dispneia, disfunção erétil, déficit visual, a própria fístula arteriovenosa e/ou cateter vascular, medo da máquina dialisadora, sentimento de culpa, mudanças na autoimagem, autoestima, perda de autonomia. Os atenuantes de estresse compreendem: apoio da família, resignação, aceitação, crença religiosa e expectativa de transplante renal.

Conclusão: $O$ estudo possibilita a identificação de estressores e fatores atenuantes de estresse nos idosos pesquisados.
\end{abstract}

Palavras-chave: insuficiência renal crônica; diálise renal; idoso; enfermagem.

\begin{abstract}
Objective: To understand and analyze stressors and stress attenuating factors experienced by elderly patients undergoing hemodialysis.

Materials and Methods: Qualitative study with 15 individuals conducted in 2010 in a northwest hospital Renal Unit of Rio Grande do Sul. Instruments of data collection: semi-structured interview, characterization data and observations in a field diary. Analysis of the results followed the precepts of content analysis.

Results: The elderly studied lives with various stressors in their daily life: food and water restrictions, impossibility to work, difficulty in accepting the disease and the treatment, need of traveling for treatment, weakness, dyspnea, erectile dysfunction, visual impairment, the arteriovenous fistula and/or the vascular catheter, fear of the dialyzing equipment, guilt feelings, changes in the self-image, self esteem, loss of autonomy. The stress attenuating factors include: family support, resignation, acceptance, religious belief and expectation of a renal transplantation.

Conclusion: The study allows identification of stressors and stress-relieving factors in the elderly patients studied.
\end{abstract}

Keywords: chronic renal insufficiency; renal dialysis; aged; nursing.

${ }^{1}$ Enfermeira. Mestre em Administração pela Universidade Federal do Rio Grande do Sul (UFRGS). Professora do Departamento de Ciências da Vida da Universidade Regional do Noroeste do Estado do Rio Grande do Sul (UNIJUÍ).

${ }^{2}$ Enfermeira. Pós-graduanda em Nefrologia pela UFRGS. Enfermeira na Unidade de Diálise do Hospital de Caridade de ljuí (HCl).

${ }^{3}$ Psicóloga e Enfermeira. Mestranda em Educação nas Ciências pela UNIJUí. Professora Substituta no Centro de Educação Superior Norte RS (CESNORS), Universidade Federal de Santa Maria (UFSM).

${ }^{4}$ Enfermeira. Professora livre docente da Universidade Federal de São Paulo (UNIFESP). 


\section{INTRODUÇÃO}

A expectativa de vida está em ascendência no mundo, conseqüentemente, conduz a alterações no perfil sócio demográfico da população. Este aumento vem acompanhado de elevado índice de doenças incapacitantes, crônicas e degenerativas ${ }^{1}$. Diante disso, uma das patologias que acometem idosos é a insuficiência renal crônica.

No que tange a qualidade de vida (QV) de pessoas com insuficiência renal, um estudo buscou avaliar diferenças entre adultos e idosos em hemodiálise, na cidade de Ribeirão Preto. Um dos fatores que justifica o aumento de pessoas com diagnóstico de Doença renal Crônica Terminal (DRCT), em tratamento dialítico, é o envelhecimento populacional, seguido dos avanços nas modalidades de tratamento, fator determinante para o aumento de idosos em início de diálise ${ }^{2}$.

A insuficiência renal classifica-se em aguda e crônica. A cronificação da respectiva doença faz com que o indivíduo se torne dependente de terapia de substituição renal, ao longo de sua vida. A mesma é uma síndrome complexa, decorrente da perda progressiva e se classifica em fase I, II, III, IV e V ${ }^{3}$.

Dados do censo de diálise da Sociedade Brasileira de Nefrologia ${ }^{4}$ mostram a prevalência de pacientes em diálise no Brasil, em 2009, de 77.589 pessoas, 90\% em hemodiálise. Dados sobre DRCT no Brasil apontam que o custo da referida modalidade de diálise é elevado e 86,7\% é mantido pelo Sistema Único de Saúde (SUS) ${ }^{5}$. As modalidades de tratamento disponíveis para a DRCT são: diálise peritoneal ambulatorial contínua (DPAC), diálise peritoneal automatizada (DAP), diálise peritoneal intermitente - (DPI), hemodiálise (HD) e transplante renal $^{6}$.

A hemodiálise visa remover resíduos metabólicos, eletrólitos e líquidos excessivos do sangue para tratar a falência renal e utiliza-se de princípios de difusão, osmose e filtração ${ }^{7}$. O referido tratamento pode desencadear frustração, ansiedade, impotência no paciente e interferir de forma negativa na percepção do mesmo referente à sua qualidade de vida. Isso se deve a vários fatores, dentre eles a necessidade de mudanças alimentares, restrição hídrica, alterações na aparência pessoal pela presença do cateter vascular ou fístula arteriovenosa (FAV), dependência da máquina, dentre outras.

No decorrer do tratamento dialítico os pacientes podem vivenciar situações indutoras de estresse, com repercussões nos diferentes âmbitos de sua vida. Diante da nova condição imposta pela doença renal, eles buscam se adaptar, de forma que o estresse não se torne nocivo e possibilite que desenvolvam formas efetivas e eficazes de enfrentá-lo.

Diante do exposto, busca-se com a pesquisa conhecer e analisar estressores e fatores atenuantes do estresse vivenciados por idosos que realizam hemodiálise.

\section{MATERIAIS E MÉTODOS}

A pesquisa é de abordagem qualitativa, desenvolvida em uma Unidade Renal de um hospital porte IV $^{8}$ de um município do noroeste do Rio Grande do Sul. Integraram a mesma 15 idosos, com idade igual ou superior a 60 anos, renais crônicos, que hemodialisam na respectiva unidade e que aceitaram participar. O número de sujeitos foi definido pelo método de exaustão e a partir do momento em que as informações começaram a se repetir, indicou o término da coleta de dados.

A coleta de dados ocorreu em setembro e outubro de 2010, com os seguintes instrumentos: dados de identificação, observação em diário de campo e entrevista semiestruturada, com duas questões: A partir do momento em que iniciaste fazer hemodiálise, quais as situações que o senhor (a) vivencia e que consideras difíceis, ou seja, estressantes? Diante dessas situações, o que o senhor (a) faz para se sentir melhor? As entrevistas foram gravadas em audiotape, transcritas na íntegra e após analisadas conforme preceitos da análise de conteúdo de Bardin $^{9}$. Os resultados são apresentados a partir das manifestações dos pacientes.

Foram observados os aspectos éticos que regem pesquisas com pessoas, conforme Resolução no 196/96 do Conselho Nacional da Saúde ${ }^{10}$. A pesquisa foi aprovada pelo Comitê de Ética em Pesquisa da Universidade Regional do Noroeste do Estado do Rio Grande do Sul (Unijuí), sob parecer consubstanciado $\mathrm{n}^{0}$ 230/2010. 


\section{RESULTADOS}

Dos 15 idosos pesquisados, nove são homens e seis são mulheres, com idade de 60-75 anos. Nove são casados, residem com cônjuge e a média de filhos é de um a quatro. Quanto ao início do tratamento hemodialítico, no período de um mês a um ano aderiram sete idosos e há mais de três anos, cinco. Quanto ao deslocamento para realização da terapia, cinco deles residem no município pesquisado, os demais em cidades da área de abrangência. Referente ao grau de instrução, três são analfabetos, nove cursaram o ensino fundamental incompleto, dois o fundamental completo e um o ensino médio completo.

A busca de apreender o conteúdo nas falas dos idosos resultou em duas categorias analíticas: O idoso em tratamento hemodialítico e o convívio com estressores no seu cotidiano; Atenuantes de estresse utilizados pelos idosos pesquisados.

Categoria 1 - O idoso em tratamento hemodialítico e o convívio com estressores no seu cotidiano.

No diálogo com os idosos emergiram vários estressores, resultantes das mudanças nos diferentes âmbitos da vida deles e vão desde o fato de não poderem trabalhar, mudanças nos hábitos alimentares, na autoimagem e autoestima, cuidados com fístula arteriovenosa (FAV) e/ou cateter vascular, dificuldade de aceitação da doença, perda de autonomia e sintomas associados à HD. E8 e E15 demonstram em suas falas o quanto o fato de não poderem trabalhar lhes atingiu.

Trabalhava e tive que parar para me tratar. Larguei tudo, passei a vegetar. Não tem trabalho que dê condições de trabalhar porque a gente só pode três vezes por semana. Tens que deixar para se tratar $e$ quem vai dar emprego? Ninguém...(E8)

Senti muita falta do trabalho, sou um imprestável, só sirvo para dar trabalho para os outros. (E15)

O fato de o idoso não poder trabalhar ou desenvolver atividades que the proporcionavam prazer antes da doença, altera a autoestima, aliada à dependência financeira e o cuidado de si. Esses sentimentos são evidenciados nas falas de E11 e E13.
Me sentia cansado, sem vontade de trabalhar, tinha a família para sustentar, imaginava que ela achava que eu era vagabundo, mas não tinha condições físicas...(E11)

Me estressa depender dos outros nas tarefas da casa. Meu marido lava roupa, limpa casa, eu não aceito isso. Homem é no trabalho fora de casa e a mulher dentro, porém hoje é ele quem faz e não me acostumo... (E13)

Os estressores referentes às mudanças nos hábitos alimentares e restrição hídrica foram os mais relatados. As falas de E4 e E12 elucidam o exposto.

Foi a mais braba, a água a gente sente falta, parece que é da cabeça, quanto mais tu vê, mais dá sede. $O$ chimarrão também não posso... (E4)

Senti enjôo da comida... Muda o estilo de vida, não tem mais domingo, não dá para comer carne assada, gorda e refrigerante... (E12)

Percebeu-se nas falas dos idosos angústia pela presença de cateter para hemodiálise e/ou da FAV e conseqüente alteração na autoimagem e autoestima. E6 e E7 manifestam esses sentimentos.

Sair na rua com isto [cateter vascular] não dá... Pessoas ficam olhando, a gente não se sente bem, prefiro não sair. (E6)

Me irritava, as pessoas não entendem que a gente se sente mal, feia, constrangida com esse tratamento... Ficava triste, me olhavam de um jeito que me sentia horrível, que nenhum velho ia me querer. (E7)

O idoso pode se sentir constrangido em decorrência do tratamento e, por vezes, restringir sua interação social e repercutir negativamente na qualidade vida e no enfrentamento da doença. Outro fato que levou os idosos dessa pesquisa vivenciar o estresse foi a dificuldade de aceitar a doença, presente em várias falas.. E8 e E9 explicitam a dificuldade de aceitar a DRCT e a HD.

Foi uma dificuldade ter que aceitar a doença, ela é ingrata e acaba contigo aos pouquinhos, vai te terminando. O mundo acabou, o que posso ter agora na vida? (E8) 
Faço de conta que não é comigo, não que não queira aceitar, mas se botar na cabeça isso morro mais ligeiro. Durmo 24hs, para mim o hoje não existe. Prefiro pensar que estou em casa dormindo, assim tenho força para levantar,caso contrário, não sei... (E9)

Já, nas falas de E5 e E7 observa-se medo da máquina por déficit de conhecimento, o que gera insegurança e sensação de estar entre a vida e a morte.

Não sabia, ninguém falou que hemodiálise era tirar sangue do corpo, só disseram que era como um rim artificial... Quando cheguei e vi aquilo achei que ia morrer mais rápido, tive muito medo! (E5)

A doutora falou que ia fazer duas sessões e ia resolver... faz oito anos que estou aqui... Imagina o que senti, nem sabia o que era a máquina, só tinha visto na televisão. Minha vida mudou...(E7)

Evidenciou-se na presente pesquisa, que alguns pacientes apresentavam déficit de conhecimento sobre seu tratamento, limitações e restrições. Esses podem ser responsáveis pela menor adesão ao tratamento, pelo fato de desconhecerem a gravidade da doença e suas conseqüências. E5 e E7 elucidam a falta de conhecimento em suas falas:

Às vezes falho, quando me sinto bem, não venho... líquido eu tomo, nem tanto água, mas chimarrão, suco, guaraná, chá... posso tomar porque urino... (E5)

Não vou fazer dieta que eles mandam, faz oito anos que me trato, nunca fiz e não morri, então não adianta.. (E7)

O deslocamento para realização de HD também foi verbalizado como estressor. A maioria reside na área de abrangência do serviço e necessita se deslocar, três vezes por semana, para realizar HD e dependem de transporte coletivo. E10 e E11 explicitam dificuldades que vivenciam.

Já estou cansada de vir de Três Passos de transporte... Da nossa região deve ter mais de 20. Se tratando aqui, saímos $9 \mathrm{~h}$ e voltamos às $18 \mathrm{~h}$. A gente termina a sessão e tem que esperar os outros. (E10)

Vir dialisar acho estressante, apesar de ser rotina, estou acostumando... Levanto as 5horas e fico esperando em Três Passos até as 8horas e de noite a gente volta, espera o transporte vir buscar. (E11)

Os sintomas físicos e psicológicos decorrentes da doença, do envelhecimento e de seu tratamento, foram mencionados como estressores. Dentre eles destacamse cansaço físico, fraqueza, dispnéia, disfunção erétil e déficit visual. Esses sintomas interferem na adaptação à terapêutica, pois eles enfrentam os sinais clínicos do envelhecimento aliados aos do tratamento, o que causa desgaste físico, emocional e piora da qualidade de vida. E4, E2, E3 e E14 explicitam o quanto é difícil vivenciar estas situações.

Saio fraco da hemodiálise, em casa tenho que deitar por causa da canseira... As forças não são mais as mesmas. (E4)

A adaptação foi difícil, muito cansaço, a mulher tinha que vir junto porque faltava ar, não dava para ficar sozinho, tinha medo de cair, desmaiar. (E2)

Sentia-me sem vigor, não tinha vontade de dormir com minha mulher, deitava no quarto ao lado, ela entendia, não foi fácil... (E3)

Sou diabético, problema de visão, circulação, rins... Depois a gente vai para debaixo da terra, estou na última fase, quase cego e dependente. (E14)

Como conseqüência do tratamento também foi mencionada por um dos idosos, a disfunção erétil, dado condizente com a literatura. Alguns idosos mencionaram sentimento de culpa pela doença, reconhecem que não tinham hábitos saudáveis, não realizavam tratamento correto para hipertensão, não seguiam orientações do tratamento de diabetes e isso gerou problema renal. Nas falas de E6 e E10 emergem esse sentimento.

Quem sabe se tivesse me cuidado mais... Agora preciso fazer hemodiálise e não sei por quanto tempo isso vai... (E6)

Tinha pressão alta e tinha que tomar remédios, tomava só quando me sentia mal e com o tempo atingiu 
os rins. Agora estou estragado, não me cuidei quando podia e, não posso voltar atrás... (E10)

A demora no diagnóstico surge como estressor, pois os idosos mencionam que se tivesse sido diagnosticada a doença quando procuraram a equipe de saúde talvez pudessem estar em tratamento conservador. O diagnóstico incorreto da DRCT pode favorecer o agravamento da doença e o início de diálise, em caráter emergencial. E11e E13, relatam como se sentiram diante da falta do diagnóstico de DRCT.

Tantos anos me tratando, com cinco, seis médicos... nenhum deles pediu exames de sangue para ver da doença e me tratavam para pressão, falta de circulação e esses pés inchados, ninguém descobria. (E11)

Fui consultar, me deram remédio para pressão, lá não tem especialista então nunca pediram exames corretos, só mediam pressão e diziam que eu tinha pressão alta. (E13)

Com base nos depoimentos obtidos na presente pesquisa, observa-se que os idosos pesquisados vivenciam inúmeros estressores no seu cotidiano e esses incluem restrições alimentar e hídrica, não poder trabalhar, dificuldade de aceitar a doença e o tratamento, deslocamento para realização do tratamento, fraqueza, dispnéia, disfunção erétil, déficit visual, a própria FAV e/ou cateter vascular, o medo da máquina dialisadora, sentimento de culpa, dentre outros.

Observa-se que os idosos em diálise vivenciam inúmeros estressores no seu cotidiano e esses incluem restrições alimentar e hídrica, não poder trabalhar, dificuldade de aceitar a doença e o tratamento, deslocamento para realização do tratamento, fraqueza, dispnéia, disfunção erétil, déficit visual, a própria FAV e/ou cateter vascular, o medo da máquina dialisadora, sentimento de culpa, dentre outros.

Categoria 2 - Atenuantes de estresse utilizados pelos idosos pesquisados.

Nas manifestações dos idosos pesquisados percebese que eles buscam alternativas para lidar com o estresse vivenciado, as quais compreendem: apoio da família, adaptação ao tratamento, resignação, fé em um Ser Superior - Deus e a expectativa de um transplante renal.

E1 e E10 explicitam a importância da família no tratamento da doença.

Não tenho encontrado tantas dificuldades porque toda a família está me apoiando para não desistir. (E1)

Quando meu marido me traz me sinto mais segura, sei o porquê de estar me tratando... Estou me tratando por eles... (E10)

É importante para o paciente conviver em meio de familiares e amigos que lhes dêem força e coragem para seguirem o tratamento, enfrentarem o medo e o sofrimento dele decorrentes. Concomitantemente, percebe-se que a família igualmente necessita ser cuidada, pois conviver com o doente, suas demandas, participar de sua trajetória, dificuldades, vitórias e derrotas podem desencadear medo, sofrimento, desgaste, angústia, dentre outros sentimentos.

E4 e E8 elucidam como transcorreu o processo de resignação e de aceitação da doença

Tem que levar como se fosse um serviço... o negócio é se cuidar para poder viver. Isso estressa, mas fazer o quê? Tem que aceitar. (E4)

A doença convive comigo o dia a dia e eu com ela, às vezes nós brigamos... Ela me suporta e eu a suporto. (E8)

Os sentimentos de aceitação misturam-se com sentimentos de resignação. E1 e E3 relatam sobre seu modo de aceitação.

Tem que levar como normal, fazer, tem que fazer... Senão morre. (E1)

Tem coisa muito pior que isso... Então tem que aceitar. Tem que vir foi assim que melhorei. Queria ser normal como os outros, mas se Deus quis assim, é porque vou ser recompensado. (E3)

A fé em um Ser Superior os ajuda a enfrentar a situação da doença crônica, irreversível, bem como a 
terapia dialítica. No diálogo com os idosos, sujeito da pesquisa evidenciou-se que em determinado momento Deus é retratado como o único Ser capaz de aliviar seu sofrimento e em outro, como o Ser que lhe impôs essa condição de saúde. E8 e E12 explicitam esse sentimento.

Agora vai até quando Deus quiser. Ele que sabe quanto tempo vou viver. O que tinha que fazer no mundo fiz, quando o Senhor quiser me levar estou aguardando. (E8)

A gente deve confiar que Deus vai ajudar todos a melhorar. A medicina é por Deus e diz na Bíblia que nós temos que seguir os regulamentos da Terra, tenho que obedecer à lei de Deus, quem sabe essa é a provação que Ele tinha para mim?! (E9)

Fica evidente o sentimento de esperança, expresso nas falas dos entrevistados. Outra alternativa que gera expectativa positiva nos idosos e que pode ser utilizada como fator atenuante de estresse é a possibilidade de realizar um transplante renal. Eles mencionam que a lista de espera é longa, que os jovens têm preferência, mas mesmo assim acreditam nesta possibilidade. E5 e E13 explicitam que tem esperança de realizar um transplante renal, mas estão cientes das dificuldades.

Tenho muita esperança de ganhar um rim, estou na fila do transplante, mas os mais novos estão ganhando primeiro... Acho que um dia vai sobrar um para mim, se Deus quiser... (E5)

A solução é o transplante, mas acho que não vem logo, é muita gente... Milhares de pessoas estão esperando por essa oportunidade. (E13)

Quando questionados sobre a possibilidade de um familiar realizar a doação do órgão, o medo emergiu. E13 e E14 falam sobre o medo em relação à doação intervivos.

Minha filha quer me doar o rim, mas não quero, ela é muito novinha, pode mais tarde fazer falta, e depois que me colocarem não dá para devolver... (E13)

Coloco em dúvida se quero o rim da minha esposa, se seria válido, por mais que trocaria uma coisa ruim por uma saudável, viveria mais... Sei que vou morrer primeiro, então fico com dúvida, avaliando, pesando se vale. (E14)

Dentre os atenuantes do estresse mencionados pelos participantes dessa pesquisa, destacam-se o apoio da família, a resignação, a aceitação, crença religiosa e expectativa de um transplante renal.

\section{DISCUSSÃO}

Mais da metade (8) dos pacientes pesquisados iniciou o tratamento hemodialítico em caráter emergencial, logo após o diagnóstico de DRCT, o que demonstra a demora das manifestações clínicas da doença e/ou do diagnóstico. Dados semelhantes foram encontrados em estudo com 45 pacientes que avaliou a adesão dos mesmos ao tratamento hemodialítico, em uma Unidade Renal, em Fortaleza. Eles concluíram que houve predomínio de pacientes do sexo masculino (65\%), casados ou em união estável (51\%), 55\% em HD há mais de cinco anos e com baixa escolaridade ${ }^{11}$.

$O$ fato de os pesquisados apresentarem dificuldades de inserção no mercado de trabalho, um estudo com 43 renais crônicos em HD em um centro de diálise de Curitiba, buscou conhecer mudanças nas atividades laborais dos pacientes. Alguns dos participantes referiram que as atividades exigiam força dos membros superiores e esse foi um limitador pela presença da FAV. Outros se reportaram ao tempo para realização da HD associado aos sintomas físicos e psicológicos ${ }^{12}$. O fato de o paciente não conseguir trabalhar por incapacidade física, pode desencadear vários sentimentos, inclusive evoluir para depressão ${ }^{13}$.

Em estudo com 16 indivíduos com DRCT de Maringá, para identificar concepções e posturas relacionadas ao trabalho, os autores destacam que a HD não implica em impedimento absoluto para o trabalho, mas causa limitações e, por vezes, afastamento das atividades laborais e, conseqüentemente, pode levar a alterações fisiológicas, psíquicas, sociais e dependência para atividades diárias $^{14}$.

Muitas vezes o tratamento hemodialítico altera os papéis e responsabilidades da família para que o 
paciente consiga aderir ao tratamento. Essa mudança pode gerar sentimentos de culpa, impotência e incapacidade, o que favorece 0 estresse ${ }^{11}$. Esses sentimentos surgem também pela readequação da nova renda familiar, que pode ser menor do que a anterior à descoberta da DRCT, tanto para ele quanto para sua família ${ }^{12}$.

Nesse sentido, a equipe de enfermagem deve orientar os pacientes e realizar atividades motivacionais para que não se sintam incapazes diante das restrições impostas pela doença. Uma melhor qualidade de vida não significa fazer tudo como antes da DRCT e sim na adaptação da vida atual e, diante desta, procurar prazer nas atividades que podem ser realizadas. O enfermeiro interage continuamente com os pacientes, portanto, tem condições de assistir o idoso com DRCT e proporcionar momentos melhores em sua vida. Para que isso ocorra considera-se importante o diálogo, buscar entender a forma de enfrentamento deste processo, como ele se sente frente à doença e conhecer suas concepções enquanto Ser cuidado.

O renal crônico em tratamento hemodialitico necessita realizar controles rigorosos no que tange a restrição hídrica e alimentar. Em pesquisa sobre autonomia de 11 renais crônicos em HD de uma das clínicas satélite de São Paulo, os autores pontuam que todos os pacientes se reportaram à dificuldade e importância de cumprir as orientações referentes à alimentação, fator decisivo para o sucesso do tratamento ${ }^{15}$. Pereira e Guedes $^{13}$ corroboram ao afirmar que essas mudanças geram angústia, sofrimento e que repercutem na relação do dia a dia dos pacientes.

A mudança nos hábitos de vida do idoso pode gerar estresse. Estudo com oito mulheres com DRCT no interior de São Paulo avaliou vivências e demandas de atenção. Relataram que para as pacientes foi difícil a adaptação às restrições hídricas, mas que com o tempo superaram e passaram a integrar o cotidiano. Elas sabem que é importante para o sucesso do tratamento, mas não negam as frustrações geradas pela mudança de hábitos ${ }^{16}$.

A presença da FAV pode gerar no paciente alterações na sua autoestima e nesse sentido, quando ele apresenta aparência física alterada, repercute nas emoções, sentimentos, autoestima e pode contribuir para o afastamento do meio social, gerar angústia e levar à depressão ${ }^{17}$. A hemodiálise causa sentimentos opostos, como amor e ódio, pois eles necessitam deste tratamento para manterem-se vivos, porém é difícil aceitar que dependem de uma máquina para que isso aconteça e o tratamento passa a ser visto como símbolo de "vida e morte"15.

O sentimento de medo da máquina por déficit de conhecimento gera insegurança e sensação de estar entre a vida e a morte. Neste tratamento o tempo atua como fator decisivo para a aceitação da doença e de que são dependentes da terapêutica, da "máquina dialisadora" ${ }^{16}$. Estudo com 10 doentes renais no Rio de Janeiro visou identificar como é o dia a dia de portadores de DRCT em HD, suas atitudes, comportamentos e práticas. Os autores destacaram a aceitação nos pacientes, pois reconheciam o tratamento e a relevância para sua saúde ${ }^{18}$.

Em pesquisa com 30 pessoas com diagnóstico de DRCT, no município de Alfenas sobre adesão ao tratamento farmacológico de uso diário, os autores concluíram que a mesma está diretamente relacionada ao reconhecimento e aceitação da condição de saúde, para assim conhecer fatores de risco e cultivar hábitos saudáveis $^{19}$. Em outro estudo ${ }^{11}$, os autores pontuam que o tratamento de substituição renal requer adesão, porém nem sempre vem associada à adaptação. O paciente, muitas vezes, não consegue adaptar-se às mudanças impostas pela doença e adere ao tratamento por saber que é o que o mantém vivo.

Dados semelhantes foram encontrados em estudo com oito renais crônicos no hospital de Alfenas. Eles buscaram entender o significado de ser dependente de HD para o paciente e concluíram que apesar dos problemas e de terem que aderir a um tratamento rigoroso, há também dificuldades para locomoção até a Unidade Renal e isso gera frustração, dependência e cansaço físico ${ }^{20}$. Estudo com 30 pacientes com DRCT no Hospital Universitário de Alfenas, identificou principais intercorrências durante uma sessão de HD. Os autores concluíram que para o doente conviver com o tratamento implica em dor, limitação, restrições, isolamento, impossibilidade de passeios devido à 
periodicidade da hemodiálise, disfunção sexual, diminuição das atividades cotidianas, cansaço físico e mental $^{20}$.

Nesse contexto, referente à necessidade de repouso, estudos apontam que é necessário, após a HD, um tempo para descanso, porém este é um dos motivos dos pacientes não conseguirem desenvolver atividades laborais $^{12}$. Outros autores se reportam as queixas constantes dos pacientes em relação á falta de energia, desânimo, fadiga, diminuição das condições físicas para tarefas cotidianas. Estes eventos ocorrem principalmente com os idosos, por apresentarem sinais do próprio envelhecimento que, associados à DRCT diminui a qualidade de vida relacionada à saúde física ${ }^{2}$.

Quanto à dispnéia, dados semelhantes foram encontrados em estudo com 72 pacientes no interior do Mato Grosso do Sul. Os autores avaliaram a função respiratória de pacientes com DRCT em HD e transplantados renais. Concluíram que a função pulmonar apresenta-se diminuída em relação à população em geral, por apresentarem maior comprometimento da função muscular e pulmonar ${ }^{21}$. Quanto ao déficit visual, autores pontuam que este afeta diretamente a qualidade de vida do idoso, pois dificulta a realização de tarefas cotidianas, origina problemas psicológicos, sociais e econômicos pela perda da autoestima $^{22}$.

Estudo no Hospital de Base de São José do Rio Preto analisou prevalência de disfunção erétil em doentes renais e obtiveram como resultado que $24 \%$ deles apresentaram disfunção erétil leve, $25 \%$ moderada e $10 \%$ impotência sexual grave. Os autores destacam que a maioria não recebe tratamento para esta patologia ${ }^{23}$.

As principais causas do encaminhamento tardio é a ausência de sinais e sintomas, resistência ao tratamento, falta de profissionais qualificados, falha do sistema de saúde e pouca estrutura para realização de exames $^{5}$. Um estudo realizado para orientar pacientes em fase pré-dialítica, para melhor compreensão das limitações impostas, destacou carências de programas para detecção precoce da DRCT, de prevenção à patologia o que reduziria custos ao sistema de saúde, desgaste e sofrimento do paciente ${ }^{24}$. Em estudo sobre necessidades de cuidado de si dos portadores de DRCT em HD e comparado com a qualidade de vida, autores afirmam que quando a hemodiálise ocorre de forma emergencial, geralmente leva a não adesão ao tratamento, pela falta de preparo dos pacientes para enfrentá-la, assim, torna-se um processo doloroso e traumático ${ }^{25}$.

Quanto aos fatores atenuantes de estresse, o suporte familiar foi o mais verbalizado, deste modo, evidencia-se que a família atua como incentivador para o idoso continuar a viver. É indispensável para adesão do tratamento o vínculo familiar, pois a ajuda e o apoio neste momento geram conforto emocional ${ }^{26}$. A doença pode resultar em fortalecimento e união entre os membros da família e, deste modo, emergir como um aspecto positivo, diante das alterações ocorridas ${ }^{14}$.

A sensação de estar apoiado por pessoas que integram sua vida faz com que não se sintam sozinhos diante da situação vivenciada ${ }^{13}$. Estudo sobre idosos em CAPD aponta que cuidar de um idoso dependente é um ato solidário, porém estressante, pois gera acúmulo de tarefas e sobrecarga de trabalho para o cuidador ${ }^{27}$.

A aceitação da doença também foi verbalizada e percebe-se que no momento que eles aceitam o diagnóstico passam a se cuidar mais e respeitar os limites e restrições impostas pela hemodiálise, com isso facilita a adesão ao tratamento. Dados semelhantes foram encontrados na literatura, em que os autores destacam que os sujeitos que reconheceram a importância do tratamento e o aceitaram, tiveram melhor qualidade de vida ${ }^{15}$.

Para Rocha e Santos ${ }^{25}$, a obrigatoriedade em aceitar a HD como única alternativa para viver gera sentimento de perda da liberdade e da qualidade de vida. Deste modo a aceitação ocorre porque o paciente necessita do tratamento e assim se sente conformado pelo fato de ter uma oportunidade de continuar a viver e vê o tratamento como recomeço e se adapta, aos poucos, à nova vida imposta pela doença ${ }^{19}$. Esse resultado vem ao encontro do estudo de Carreira e Marcon ${ }^{14}$, ao pontuarem que os sentimentos de conformação surgem como alternativa de entender que o tratamento é a única forma de sobrevivência.

Esses sentimentos vão ao encontro dos resultados de estudos $^{14,20}$, os quais reconhecem 0 apego dos 
pacientes à religiosidade, a crença de que somente Deus pode trazer benefícios à sua vida, sentindo-se gratos pela oportunidade de estarem vivos, devido a hemodiálise. Pesquisa para identificar sentimentos de nove pacientes renais crônicos, em HD, referentes ao transplante renal, apontam que a demora causa angústia e ansiedade devido à incerteza de conseguir um doador ${ }^{28}$.

Quanto ao sentimento de medo, os pacientes se sentem culpados com a possibilidade de um transplante renal de doador vivo e manifestam recusa do órgão pelas chances de o familiar vir a desenvolver DRCT devido à doação, o que causaria sentimento de culpa no receptor $^{28}$.

Realizar essa pesquisa tornou possível conhecer e analisar os estressores vivenciados por 15 idosos que hemodialisam em uma Unidade Renal do noroeste do Rio Grande do Sul, bem como os fatores atenuantes utilizados por eles para lidar com o estresse.

Os idosos, sujeitos da pesquisa, possuem idade entre 60 a 75 anos, baixa escolaridade, nove são casados, um deles não possui filhos, dez residem em cidades da área de abrangência do referido serviço. Considera-se que o baixo grau de escolaridade dos participantes pode ser um dos fatores contribuintes para o estresse e a baixa da adesão ao tratamento, principalmente pelo déficit de conhecimento referente à doença e ao tratamento, as dificuldades de assimilar as informações da equipe, visto que deste modo, ocorre aumento dos riscos de danos à saúde.

Os idosos pesquisados vivenciam inúmeros estressores no seu cotidiano que podem interferir tanto na adaptação ao tratamento quanto na sua qualidade de vida. Dentre os estressores vivenciados destacam-se as restrições, limitações e disfunções, os cuidados com a FAV e/ou cateter vascular, perda da autonomia, alterações na autoimagem e autoestima, dificuldade de aceitar a doença, dentre outros. Alguns destes estressores podem ser minimizados pela equipe de saúde, no momento em que ela identifica as necessidades de cada paciente, favorece, personaliza e qualifica a assistência.

Quanto aos atenuantes de estresse utilizados pelos sujeitos pesquisados, destaca-se o apoio familiar, pois a família é citada como um dos motivos pelo qual o idoso aceitou fazer o tratamento, além de ser o seu principal cuidador. Outro atenuante mencionado foi a fé em um Ser Superior, que se justifica pelo fato de serem portadores de uma patologia que não tem cura, pelo medo constante da morte, a instabilidade e o sofrimento de ser dependente de uma máquina, dentre outros.

$\mathrm{Na}$ busca pela assistência humanizada está implícita a necessidade de organizar o trabalho de forma a favorecer uma assistência direcionada a necessidade individual de cada idoso e familiar, deste modo exige-se cada vez mais a atuação de profissionais competentes e habilitados.

Os resultados desta pesquisa igualmente mostram complicações clínicas e psíquicas que, de alguma forma, permeiam as respostas dos pacientes e suas respectivas análises. Os resultados obtidos podem sugerir medidas que visem incrementar situações atenuantes do estresse, como melhorar o apoio familiar, reuniões da equipe da diálise com familiares, programação de atividades conjuntas com pacientes, familiares e profissionais, atividades educativas para facilitar a adaptação e adesão ao tratamento.

Os resultados desta pesquisa visam instigar profissionais da saúde, estudantes e demais profissionais envolvidos na assistência desse contingente populacional expressivo a refletirem e sistematizarem ações envolvendo a temática, cientes da complexidade que envolve o cuidado.

No que tange especificamente à equipe de enfermagem que atua com o doente renal crônico, em especial, aos enfermeiros, esses resultados podem instigar reflexões, discussões, ampliar conhecimentos e auxiliá-los na realização da sistematização da assistência de enfermagem (SAE) no planejamento de cuidados para o paciente, no sentido de ajudá-lo no enfrentamento, a partir do reconhecimento dos seus sentimentos em relação a sua condição de saúde e adoção de novas posturas.

Considera-se importante um acompanhamento da equipe multiprofissional ao paciente, extensivo aos seus familiares, com a finalidade de avaliar aspectos psicológicos, sociais e clínicos, ciente de que o estresse influencia tanto na adesão ao tratamento do idoso 
quanto na vida pessoal do cuidador e, consequentemente, na qualidade do cuidado prestado.

\section{REFERÊNCIAS}

1. Celich KLS, Galon C. Dor crônica em idosos e sua influência nas atividades da vida diária e convivência social. Rev Bras Geriatr Gerontol. 2009;12(3):345-59.

2. Kusumoto L, Marques S, Hass VJ, Rodrigues RAP. Adultos e idosos em hemodiálise: avaliação da qualidade devida relacionada à saúde. Acta Paul Enferm. 2008;21(n. esp):152-9.

3. Draibe AS, Ajzen H. Insuficiência Renal Crônica (IRC). In: Ajzen $\mathrm{H}$, Schor N. Guia de medicina ambulatorial e hospitalar UNIFESP. São Paulo: Manole; 2005.

4. Sociedade Brasileira de Nefrologia - SBN. Censo de Diálise SBN [online]. 2009 [capturado 2011 Jun 10] Disponível em: http://www.sbn.org.br/pdf/ censo_SBN_2009_final.pdf

5. Sesso R, Gordan P. Dados disponíveis sobre a doença renal crônica no Brasil. J Bras Nefrol. 2007;29(supl):9-12.

6. Martins MRI, Casemiro CB. Qualidade de vida de pessoas com doença renal crônica em tratamento hemodialítico. Rev. Latino-am Enfermagem. [periódico online]. 2005 Set/Out [capturado 2011 Jun 10]; 13(5):[7 telas] Disponível em: http://www.scielo.br/pdf/rlae/v13n5/v13n5a10.pdf

7. Lenardet $\mathrm{MH}$, Borghi ACS, Seima MD, Hammerschmidt $\mathrm{KSA}$, Michel $\mathrm{T}$ et al. $\mathrm{O}$ cuidado gerontogeriátrico em unidade de tratamento hemodialítico. Cogitare Enfermagem 2009;14(1):37-43.

8. Brasil. Ministério da Saúde. Portaria no 2.224/GM em 5 de dezembro de 2002. Estabelece o sistema de Classificação Hospitalar do SUS. Brasília: Ministério da Saúde; 2002.

9. Bardin L. Análise de conteúdo. Lisboa: Edições 70; 2009.

10. Brasil. Conselho Nacional de Saúde. Resolução 196/96. Diretrizes e normas regulamentadoras de pesquisas envolvendo seres humanos. Brasília: Ministério da Saúde; 1996.

11. Medeiros AC, Machado PDLC, Bonfim IM, Braqueais AR, Lima FET et al. Adesão de portadores de insuficiência renal crônica ao tratamento de hemodiálise. Acta Paul Enferm. 2010;23(4):546-51.

12. Lara EA, Sarquis LMM. O paciente renal crônico e sua relação com 0 trabalho. Cogitare Enfermagem. 2004;9(2):99-106.

13. Pereira LD, Guedes MVC. Hemodiálise: a percepção do portador renal crônico. Cogitare Enfermagem. 2009;14(4):689-95.

14. Carreira L, Marcon SS. Cotidiano e trabalho: concepções de indivíduos portadores de insuficiência renal crônica e seus familiares. Rev Latino-am Enfermagem. 2003;11(6):823-31.

15. Araujo ES, Pereira II, Anjos MF. Autonomia do paciente com doença renal crônica em tratamento hemodialítico: a aceitação como fator decisório. Acta Paul Enferm. 2009;22(n. esp):509-14.
16. Reis CK, Guirardello EB, Campos CJG. O indivíduo renal crônico e as demandas de atenção. Rev Bras Enferm. 2008; 61(3):336-41.

17. Costa PB, Vasconcelos KFS, Tassitano RM. Qualidade de vida: pacientes com insuficiência renal crônica no município de Caruaru, PE. Fisioter Mov 2010;23(3): 46171.

18. Barbosa GS, Valadares GV. Hemodiálise: estilo da vida e a adaptação do paciente. Acta Paul Enferm. 2009;22(n. esp): 524-27.

19. Terra FS, Costa AMDD, Figueiredo ET, Morais AM, Costa $M D$, Costa RD. Adesão ao tratamento farmacológico de uso diário de pacientes renais crônicos submetidos à hemodiálise. Rev Bras Clin Med. 2010;8(2):119-24.

20. Terra FS, Costa AMDD, Ribeiro CCS, Nogueira CS, Prado JP, Costa MD, Costa RD, Figueiredo ET, Morais AM. O portador de insuficiência renal crônica e suas dependências ao tratamento hemodialítico: compreensão fenomenológica. Rev Bras Clin Med. 2010;8(4):306-10.

21. Cury JL, Brunetto AF, Aydos RD. Efeitos negativos da insuficiência renal crônica sobre a função pulmonar e a capacidade funcional. Rev Bras Fisioter. 2010;14(2):91-8.

22. Carlos AP, Hamano IH, Travesolo CF. Prevalência de quedas em idosos institucionalizados no Lar das Vovozinhas e Lar dos Vovozinhos da cidade de Londrina. Rev Kairós. 2009;12(1):181-96.

23. Yassumoto G, Bezerra CS, Facio Junior FN, Azoube LR. Avaliação da função erétil e da qualidade de vida sexual em pacientes com insuficiência renal crônica em tratamento dialítico no Hospital de Base de São José do Rio Preto - FAMERP. Arq Ciênc Saúde. 2004;11(2):2-4.

24. Pacheco SG, Santos I. Cuidar de cliente em tratamento conservador para doença renal crônica: apropriação da Teoria de Orem. Rev. Enferm UERI 2005;13(2):257-62.

25. Rocha RPF, Santos I. Necessidades de autocuidado entre clientes com doença renal crônica: revisão integrativa da literatura. Rev de Pesq Cuidado Fund 2009;1(2):423-33.

26. Rocha ML, Vieira SS, Braga SO, Poveda BV, Sanchez $\mathrm{EH}$. Início do tratamento hemodialítico: qualidade de vida, sentimentos e dificuldades. Rev Enferm UFPE On Line. [periódico online]. 2009 [capturado 2011 Jun 10];3(2):[7 telas] Disponível em: http://www.ufpe.br/ revistaenfermagem/index.php/revista/article/view/285/281

27. Ribeiro DF, Marques S, Kusumota L, Ribeiro RCHM. Processo de cuidar do idoso em Diálise Peritoneal Ambulatorial Contínua no domicílio. Acta Paul Enferm. 2009;22(6):761-6.

28. Flores RV, Thomé EGR. Percepções do paciente em lista de espera para o transplante renal. Rev Bras Enferm. 2004;57(6):687-90.

\section{Endereço para correspondência:}

Eniva Miladi Fernandes Stumm

Rua vinte de setembro $n^{\circ} 902$

ljuí/RS - CEP 98700-000

Telefone: +55 5599717239

E-mail: eniva@unijui.edu.br 